\title{
Fate of nonreplaced sinuses of Valsalva in bicuspid aortic valve disease
}

\author{
Chan B. Park, MD, ${ }^{\mathrm{a}, \mathrm{b}}$ Kevin L. Greason, MD, ${ }^{\mathrm{a}}$ Rakesh M. Suri, MD, ${ }^{\mathrm{a}}$ Hector I. Michelena, MD, \\ Hartzell V. Schaff, MD, ${ }^{a}$ and Thoralf M. Sundt III, MD ${ }^{\mathrm{a}}$
}

\begin{abstract}
Objective: There is growing consensus that the ascending aorta should be replaced at the time of aortic valve replacement for bicuspid aortic valve even if it is only moderately dilated; the natural history of nonreplaced sinuses of Valsalva is less clear.
\end{abstract}

\begin{abstract}
Methods: We identified patients without defined connective tissue disorder undergoing primary aortic valve replacement for bicuspid aortic valve and separate repair of the ascending aorta without root replacement at the Mayo Clinic between January 1, 1988, and December 31, 2007.

Results: Among 218 patients, 65 underwent ascending aortoplasty and 153 underwent separate graft replacement of the ascending aorta. Of the latter group, 15 also had graft replacement of the noncoronary sinus. The mean age at operation was $62 \pm 13$ years. Valvular dysfunction was predominantly stenosis in 151 patients $(70 \%)$, regurgitation in 54 patients $(25 \%)$, and mixed in 12 patients $(5 \%)$. At a follow-up of up to 17 years (median, 3.3 years; range, $0-17$ years), 10 patients $(5 \%)$ had undergone late reoperation, of whom 1 had replacement of the ascending aorta and 1 had replacement of the root for significant dilatation of the sinuses. Both patients had originally undergone aortoplasty. No other patient required root surgery. One-, 5-, and 10-year freedom from reoperation for any cause were $97.6 \%, 94.9 \%$, and $85.5 \%$, respectively.

Conclusions: Although progressive ascending aortic dilatation after aortic valve replacement for bicuspid aortic valve is well documented, progressive dilatation of nonreplaced sinuses is not evident. Separate valve and graft repair remains a reasonable surgical option in the setting of aortic valve replacement for bicuspid aortic valve with ascending aortic dilatation provided the sinuses of Valsalva are not significantly enlarged. (J Thorac Cardiovasc Surg 2011;142:278-84)
\end{abstract}

Bicuspid aortic valve (BAV) is the most common congenital valvular heart disease, affecting $0.9 \%$ to $2.0 \%$ of the general population, ${ }^{1}$ and the underlying pathology responsible for aortic valve replacement (AVR) in as many as one third of patients in the United States. ${ }^{2}$ BAV is associated with ascending aortic dilatation and enlargement of the aortic valve annulus in as many as half of all individuals. ${ }^{3-8}$ Furthermore, ascending aortic dilatation may progress even after successful AVR. ${ }^{9}$ Because ascending aortic dilatation is a widely recognized risk factor for aortic dissection, ${ }^{10}$ and patients with $\mathrm{BAV}$ are overrepresented in autopsy series of aortic dissection, ${ }^{11}$ a more aggressive posture toward replacement of the moderately enlarged ascend-

From the Divisions of Cardiovascular Surgery, ${ }^{\text {a }}$ Mayo Clinic, Rochester, Minn; Department of Thoracic and Cardiovascular Surgery, ${ }^{\text {b }}$ St Paul's Hospital, The Catholic University of Korea, Seoul, Korea; and Divisions of Cardiovascular Medicine, ${ }^{\mathrm{c}}$ Mayo Clinic, Rochester, Minn.

Disclosures: Authors have nothing to disclose with regard to commercial support.

This manuscript was presented at the Aortic Symposium 2010, New York, New York, April 29-30, 2010, as part of the POD (presentation on demand) portion of the meeting.

Received for publication April 29, 2010; revisions received Aug 7, 2010; accepted for publication Aug 29, 2010; available ahead of print Nov 1, 2010.

Address for reprints: Thoralf M. Sundt III, MD, Mayo Clinic, 2001 st St SW, Rochester MN, 55905 (E-mail: sundt.thoralf@mayo.edu).

J Thorac Cardiovasc Surg 2011;142:278-84

$0022-5223 / \$ 36.00$

Copyright $(c) 2011$ by The American Association for Thoracic Surgery

doi:10.1016/j.jtcvs.2010.08.055 ing aorta has been advocated in the most recent American College of Cardiology/American Heart Association guidelines for the treatment of valvular heart disease. ${ }^{12}$

Although progressive dilatation of the ascending segment is well documented, the risk of progressive dilatation of the sinuses of Valsalva is less clear. The issue has practical significance because replacement of the sinuses either as part of a composite root replacement or as a full valvesparing root mandates reimplantation of the coronary arteries. Although these procedures are reported to carry low operative risk by centers with large experience, ${ }^{13-15}$ data suggest that the risk is higher in the community at large. In a study from the Society of Thoracic Surgeons database, the incremental risk ratio associated with root replacement relative to isolated AVR was $2.78 .{ }^{16}$ Complications related to coronary artery reimplantation occur, even in experienced hands. ${ }^{17}$ The hazards of this approach can be expected to be higher if a particularly aggressive prophylactic approach is advocated in patients even when the sinuses are not particularly enlarged because mobilization and reimplantation of the nondisplaced coronary ostea will be more difficult. Furthermore, if subsequent reoperation is required either because a young patient opts for a bioprosthesis or a mechanical valve becomes infected or obstructed by pannus, reoperative root replacement can be expected to carry a higher risk than reoperative AVR. ${ }^{18}$ 


\section{Abbreviations and Acronyms \\ $\mathrm{AVR}=$ aortic valve replacement \\ $\mathrm{BAV}=$ bicuspid aortic valve \\ $\mathrm{HR}=$ hazard ratio}

The alternative procedure to root replacement, a separate valve and graft, obviates the risks associated with coronary reimplantation but leaves the patient at potential risk of subsequent sinus dilatation. A small series previously reported suggested that late complications associated with separate valve and graft were uncommon; however, follow-up was limited. ${ }^{19}$ In the interest of further exploring this question with a larger data set over a longer follow-up interval, we examined our institutional experience with the late dilation of nonreplaced sinuses of Valsalva after separate valve and aortic repair in the setting of BAV disease.

\section{MATERIALS AND METHODS}

This study was approved by institutional review board of the Mayo Clinic. All patients gave consent for inclusion in clinical research projects, and study specific consent was waived. Patients with BAV undergoing primary separate AVR and repair of the ascending aorta by graft replacement or aortoplasty between January 1, 1988, and December 31, 2007, were identified via search of our prospectively managed, Society of Thoracic Surgeons-compliant computerized clinical database. Patients with defined connective tissue disorders (Marfan syndrome or Ehlers-Danlos syndrome) were excluded, as were those with concomitant procedures on other valves. Perioperative data were collected from the database and retrospective review of medical records, including echocardiographic reports, pathology reports, and all operative records. When possible, aortic root and ascending aortic sizes were determined from preoperative and the most recent echocardiograms. There is no uniform policy at the Mayo Clinic regarding size criteria for replacement of the sinuses, and it is therefore likely that some mildly or even moderately enlarged sinuses were left intact. In more recent years the approach has been more aggressive, including replacement of the noncoronary sinus when enlarged with a tongue extension of graft material (Figure 1). Long-term follow-up information was obtained by postal survey.

\section{Statistical Analysis}

Descriptive statistics were presented as mean \pm standard deviation for continuous variables and frequency and percentage for categoric variables. Preoperative and postoperative aortic root sizes were compared by paired $t$ test. Kaplan-Meier method was used to draw survival curves and calculate 5- and 10-year survival statistics and freedom from reoperation. Cox regression models were used to find the univariate and multivariate predictors of survival. Variables significant by univariate analysis $(P<.05)$ were considered in the multivariable model, with model selection using the stepwise method (backward and forward methods resulted in the same model). All statistical tests were 2 sided with the alpha level set at 0.05 for statistical significance. Analysis were performed using SAS (SAS Institute Inc, Cary, NC).

\section{RESULTS}

The mean age at the time of surgery was $61.5( \pm 13.0)$ years (Table 1). Male patients predominated $(75 \%)$. Of note, $55 \%$ were smokers, $61 \%$ had hypertension, and
$61 \%$ had hypercholesterolemia. Only 8 patients $(3.7 \%)$ had a history of aortic coarctation. The dominant functional valvular disease was stenosis in $70 \%$ of patients and insufficiency in $25 \%$ of patients. The pattern of cusp fusion by echocardiography or observation at the time of operation was left and right cusp fusion in 132 patients $(84 \%)$, right and noncoronary cusp fusion in 24 patients $(15 \%)$, and left and noncoronary cusp fusion in 2 patients $(1.3 \%)$. Eighty-eight percent of patients had an identifiable raphe, and $64 \%$ of patients had asymmetric cusps. Unfortunately, data were not collected prospectively with regard to root dimensions or phenotype.

\section{Operative}

As shown in Table 2, at surgery 153 patients underwent graft replacement of the ascending aorta and 65 patients underwent ascending aortoplasty. The choice between these procedures, as was the choice between separate valve and graft versus root replacement, was by the operating surgeon and not by strict diameter criteria. There is no uniform institutional policy with regard to the procedure performed, although aortoplasty is currently less common. Among patients with graft replacement of ascending aorta, the noncoronary cusp was replaced or repaired in 15 patients $(6.9 \%)$ because of asymmetric enlargement. Concomitant hemi-arch or total aortic arch replacement was performed in 13 patients $(6.0 \%)$. Mechanical and biological prostheses were used in equal numbers. The mean age was $67 \pm 13$ years for those receiving biological prostheses and $56 \pm$ 10 years for those receiving a mechanical valve. During this same time interval, 147 patients with BAV underwent full root replacement.

\section{Early Outcome}

The operative mortality was $2.8 \%$ (6 patients). Fourteen patients underwent reoperation for bleeding $(6.6 \%)$. Postoperative intraaortic balloon pump support was used in 8 patients $(3.8 \%)$, and 19 patients required ventilation for more than 24 hours $(9.0 \%)$. Three patients $(1.4 \%)$ had transient ischemic attacks, and 5 patients $(2.4 \%)$ had permanent stroke. Three patients had postoperative renal failure with an increase of serum creatinine to greater than $2.0 \mathrm{mg} / \mathrm{dL}$ or a doubling of the preoperative creatinine, or the institution of dialysis $(1.4 \%)$. Two patients had postoperative sepsis $(0.9 \%)$.

\section{Late Outcomes}

The follow-up was to a maximum of 17.2 years, with a median of 3.3 years. The completeness of follow-up by Clark's equation ${ }^{20}$ was $79 \%$. During follow-up, 10 patients underwent late reoperation for a variety of indications (Table 3). There were no late reoperations for aortic root dissection or rupture. A 67-year-old male patient who had undergone AVR for aortic stenosis and reduction aortoplasty, as well 


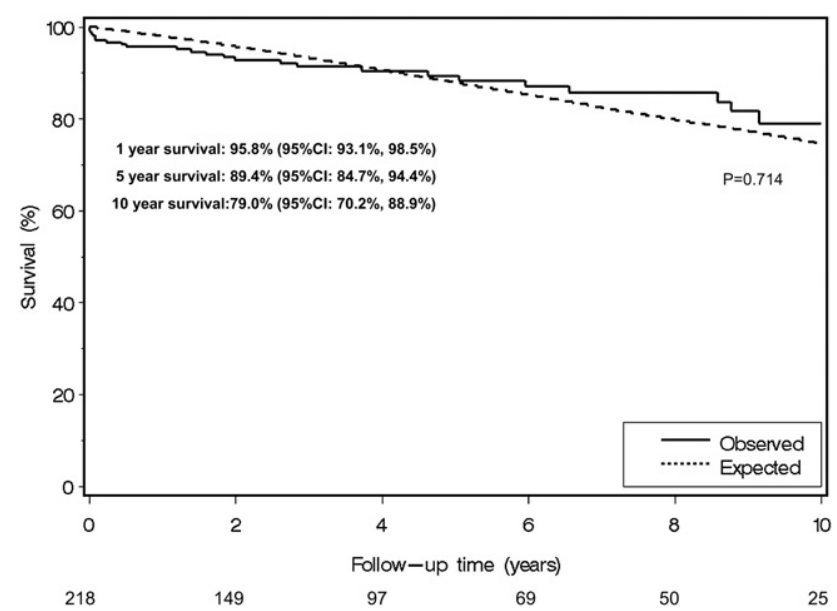

FIGURE 1. Freedom from late reoperation among patients with BAV disease undergoing separate AVR and repair of ascending aorta. CI, Confidence interval.

as coronary bypass, returned for graft replacement of the ascending aorta and root 9 years later for enlargement of the ascending aorta to $63 \mathrm{~mm}$. No computed tomography scan is available from the time of his original operation, nor are there recorded measurements of his root at surgery. His operative note mentions only dilatation of the ascending aorta. At reoperation both the ascending aorta and root were enlarged. The ascending aorta and root were replaced with a Dacron tube graft sewn to the well-functioning aortic prosthesis. A second patient underwent graft replacement of the ascending aorta after prior aortoplasty. Overall, as shown in Figure 1, freedom from late reoperation was $97.6 \%, 94.9 \%$, and $85.5 \%$ at 1,5 , and 10 years, respectively.

TABLE 1. Preoperative patient characteristics

\begin{tabular}{lc}
\hline \multicolumn{1}{c}{ Variable } & Frequency* \\
\hline Age (y) & $61.5 \pm 13.0$ \\
Sex (male) & $75.2 \%(164)$ \\
Smoke & $55.0 \%(120)$ \\
Diabetes mellitus & $10.1 \%(22)$ \\
Hypercholesterolemia & $60.6 \%(131)$ \\
Preoperative renal failure & $2.3 \%(5)$ \\
Hypertension & $60.6 \%(131)$ \\
Cerebrovascular accident & $2.3 \%(5)$ \\
Peripheral vascular disease & $9.3 \%(20)$ \\
NYHA (III/IV) & $39.0 \%(82)$ \\
Coronary artery disease & $30.7 \%(67)$ \\
History of coarctation of aorta & $3.7 \%(8)$ \\
Previous CABG & $4.6 \%(10)$ \\
Dominance of AV disease & \\
$\quad$ Aortic stenosis & $69.6 \%(151)$ \\
$\quad$ Aortic insufficiency & $24.9 \%(54)$ \\
$\quad$ Mixed & $5.5 \%(12)$ \\
EF $(\%)$ & $59.5 \pm 11.7$ \\
\hline$N Y H A$, New York Heart Association; $C A B G$, coronary artery bypass graft; $A V$, aortic \\
valve; $E F$, ejection fraction. ${ }^{*}$ Continuous variable was expressed as mean \pm standard \\
deviation.
\end{tabular}

TABLE 2. Operative characteristics

\begin{tabular}{lc}
\hline \multicolumn{1}{c}{ Variable } & Frequency* \\
\hline ACC time (min) & $68.8 \pm 28.9$ \\
CPB time (min) & $96.0 \pm 43.7$ \\
Circulatory arrest time (min) & $18.5 \pm 13.2$ \\
Operative procedures & \\
NCC replace/plasty & $6.9 \%(15)$ \\
Ascending aortoplasty & $29.8 \%(65)$ \\
Ascending aorta graft replacement & $70.2 \%(153)$ \\
Hemiarch replacement & $5.0 \%(11)$ \\
Total arch replacement & $0.9 \%(2)$ \\
Descending aorta replacement & $0.5 \%(1)$ \\
Type of valve & \\
Mechanical & $50.0 \%(109)$ \\
Bioprosthetic & $50.0 \%(109)$ \\
\hline$A C C$, Aortic crossclamp; $C P B$, cardiopulmonary bypass; $N C C ;$ noncoronary cusp. \\
*Continuous variable was expressed as mean \pm standard deviation.
\end{tabular}

A total of 28 patients (12.8\%) died during follow-up, in whom the cause was known to be cardiac in $5(17.9 \%)$ and noncardiac in $11(39.3 \%)$. Causes of death were unknown in 12 patients $(42.9 \%)$. The overall survivals for all patients were $95.8 \%, 89.4 \%$, and $79.0 \%$ at $1,5,10$ years, respectively (Figure 2). Predictors of overall survival by multivariate analysis were age (hazard ratio [HR], 1.07; $P=.001$ ), diabetes mellitus (HR, 5.32; $P<.001$ ), preoperative renal failure (HR, 8.43; $P=.001$ ), and New York Heart Association III/IV (HR, 2.28; $P=.04)$, as shown in Table 4. Use of a bioprosthetic valve at the initial operation appeared in univariate but not multivariate analysis, likely because bioprosthetic valves were used in older patients.

Paired echocardiograms preoperatively and at least 3 months postoperatively with adequate measurements of the sinus diameter were available for 34 patients at a mean of $5.0 \pm 4.2$ years. Of these, 6 had replacement of their noncoronary sinus. As shown in Figure 3, among those patients without a noncoronary sinus procedure $(\mathrm{n}=28)$, the measured diameter of sinuses of Valsalva decreased slightly from a mean of $42.0 \pm 5.3 \mathrm{~mm}$ preoperatively to $40.1 \pm 5.1 \mathrm{~mm}$ postoperatively $(P=.006)$. When expressed as change in diameter versus time as shown in Figure 4, no relationship is apparent. As expected, the diameter of the aortic annulus did not differ between preoperative and postoperative echocardiographic studies (mean, $24.7 \pm 3.1 \mathrm{~mm}$ vs $23.8 \pm 1.9 \mathrm{~mm} ; P=.39$ ); however, the diameter of the sinotubular junction (mean, $34.6 \pm 8.4 \mathrm{~mm}$ vs $31.6 \pm 9.7$ $\mathrm{mm} ; P=.02)$ and the ascending aorta $(50.0 \pm 6.7 \mathrm{~mm}$ vs $36.8 \pm 6.8 \mathrm{~mm} ; P<.001$ ) were significantly decreased after operation.

\section{DISCUSSION}

The results of this study indicate that although enlargement of the ascending aorta after AVR for BAV occurs with sufficient frequency to be clinically apparent, 
TABLE 3. Details for reoperations

\begin{tabular}{|c|c|c|c|c|c|}
\hline Age, $y$ & Gender & Interval $(y)$ & Primary operation & Reason for reoperation & Title of reoperation \\
\hline 75 & M & 0.9 & $\mathrm{AVR}+\mathrm{AscAo}$ replacement & Mediastinitis & AscAo replacement with valveless homograft \\
\hline 75 & M & 0.3 & $\mathrm{AVR}+\mathrm{AscAo}$ replacement & PVE & Homograft replacement of aortic root \\
\hline 71 & M & 0.3 & $\mathrm{AVR}+\mathrm{AscAo}$ replacement & PVE & AVR \\
\hline 67 & M & 9.2 & $\mathrm{AVR}+$ aortoplasty $+\mathrm{CABG}$ & $\begin{array}{l}\text { Dilatation of aortic root } \\
\text { and AscAo }\end{array}$ & $\begin{array}{l}\text { Graft replacement of aortic root and } \\
\text { AscAo }\end{array}$ \\
\hline 65 & M & 3.8 & AVR + aortoplasty & PVE & $\begin{array}{l}\text { Homograft replacement of aortic root and } \\
\text { CABG }\end{array}$ \\
\hline 65 & M & 1.5 & AVR + aortoplasty & RCA aneurysm & CABG \\
\hline 63 & M & 1.3 & $\begin{array}{l}\text { AVR }+ \text { AscAo replacement }+ \\
\text { PFO closure }\end{array}$ & Periprosthetic leakage & Repair of periprosthetic leakage \\
\hline 60 & M & 0.1 & $\begin{array}{l}\mathrm{AVR}+\text { total arch }+ \text { proximal descending } \\
\text { aorta replacement }+\mathrm{CABG}\end{array}$ & Thoracoabdominal aneurysm & Replacement of thoracoabdominal aorta \\
\hline 49 & M & 13.2 & AVR + aortoplasty & PPM & $\mathrm{AVR}+\mathrm{CABG}$ \\
\hline 40 & M & 9.0 & AVR + aortoplasty & PPM and AscAo dilatation & $\mathrm{AVR}+\mathrm{AscAo}$ replacement \\
\hline
\end{tabular}

$\overline{A V R}$, Aortic valve replacement; $P P M$, patient-prosthesis mismatch; $C A B G$, coronary artery bypass grafting; $A s c A o$, ascending aorta; $R C A$, right coronary artery; $P V E$, prosthetic valve endocarditis; $P F O$, patent foramen ovale.

progressive enlargement of the sinuses of Valsalva seems to be uncommon. Among the study population reported in this article, with a follow-up period of up to 17 years, there were no known instances of root rupture or dissection, and no evidence of progressive sinus enlargement by echocardiography in the subset with serial examinations. Of 218 patients in the study, only 2 underwent reoperation for replacement of the ascending aorta, 1 of whom had root replacement at the reoperation; both had undergone ascending aortoplasty, not graft replacement, at the original operation. These data suggest that, in clinical practice, those sinuses thought by an operating surgeon at the time of AVR not to be sufficiently enlarged to justify formal root replacement seldom lead to reoperation. Therefore, although prophylactic replacement of the moderately ascending aorta is strongly recommended at the time of AVR, a more circumspect posture toward routine aortic root replacement is appropriate. Composite root replacement is a well-established procedure; however, it is

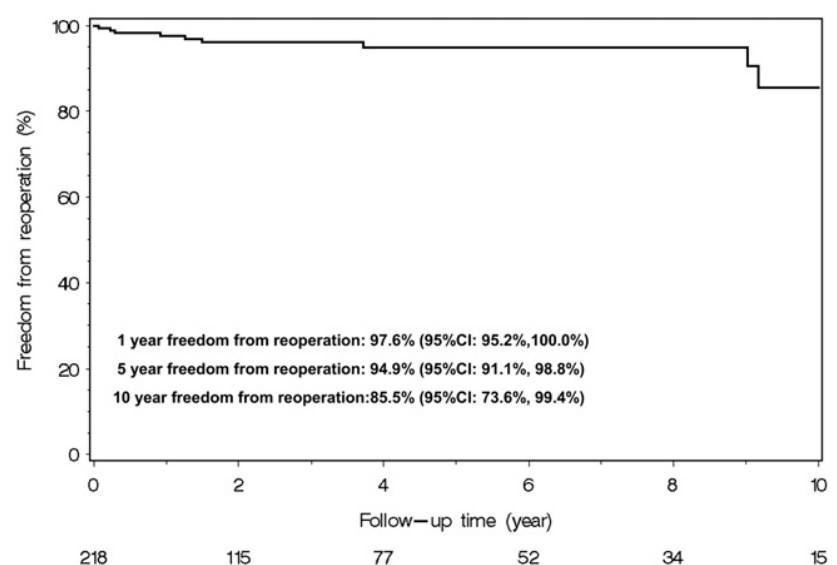

FIGURE 2. Overall survival in patients with BAV disease undergoing separate AVR and repair of ascending aorta and the survival of an age- and gender-matched Minnesota population. CI, Confidence interval. technically more challenging and carries risks of coronary osteal complications, including bleeding, kinking, and false aneurysm formation. ${ }^{21}$ Given the frequency of AVR for BAV, any unnecessary incremental increase in risk applied globally will have a powerful clinical impact. Therefore, although clearly dilated sinuses of Valsalva should not be left unaddressed, a separate valve and graft remains an appropriate procedure for some patients with BAV and ascending aortic dilatation without significant root enlargement. ${ }^{19}$

The findings of this study are consistent with an earlier, smaller study from another institution that also showed a place for separate valve and graft alongside root replacement as options in the management of BAV disease associated with aortopathy. ${ }^{19}$ We believe that this is because the aortopathy associated with $\mathrm{BAV}$ is phenotypically heterogeneous, with some aneurysms appearing to be entirely supracoronary and others involving the root much as one may see in Marfan syndrome (Figure 4). An intermediate phenotype is also observed with effacement of the sinotubular junction and generalized enlargement of both the ascending aorta and root, as well as proximal arch in many cases. Much of the existing literature fails to account for this heterogeneity, focusing on mean aortic diameters rather than identifying subsets. There is also room for confusion given loose application in the literature of segmental anatomic terminology for pathology of the root versus the ascending aorta.

A conservative view of replacement of the sinuses is also supported by literature demonstrating a somewhat slower rate of enlargement of the sinuses of Valsalva of between 0.03 and $0.91(\mathrm{~mm} / \mathrm{y})$ compared with the ascending aorta at 0.18 to $1.18(\mathrm{~mm} / \mathrm{y})$, perhaps because of different hemodynamic stresses. ${ }^{9,22-26}$ Furthermore, although an argument for prophylactic repair of the ascending aorta may be made based on the concept of a generalized aortopathy, ${ }^{27}$ clinical experience indicates that the aortopathy in BAV disease is segmental. For example, involvement of the descending 
TABLE 4. Univariate and multivariate analyses for overall survival

\begin{tabular}{lccccr}
\hline & \multicolumn{3}{c}{ Univariate } & \multicolumn{2}{c}{ Multivariate } \\
\cline { 2 - 5 } & HR & CI & $\boldsymbol{P}$ value & HR & \multicolumn{1}{c}{ CI } \\
\hline Age & 1.08 & $0.03-1.12$ & .001 & 1.07 & $1.03-1.12$ \\
DM & 4.99 & $2.06-12.07$ & $<.001$ & 5.32 & $2.12-13.3$ \\
Preoperative RF & 6.86 & $2.02-23.3$ & .002 & 8.43 & $2.36-30.1$ \\
NYHA (III/IV) & 2.41 & $1.1-5.27$ & .028 & 2.28 & $1.02-5.1$ \\
CAD & 3.62 & $1.7-7.71$ & $<.001$ & .001 \\
Bioprosthetic valve & 2.47 & $1.13-5.4$ & .023 & & .044 \\
\hline
\end{tabular}

$H R$, Hazard ratio; $C I$, confidence interval; $D M$, diabetes mellitus; $R F$, renal failure; $N Y H A$, New York Heart Association; $C A D$, coronary artery disease; $E F$, ejection fraction.

thoracic aorta is uncommon in the absence of coarctation and, whereas Stanford type A dissections appear 10-fold over-represented among patients with BAV, type B dissection is not. ${ }^{11}$

Our data may be taken to be at variance with those of others, who have recommended full root replacement in patients with BAV with aortic valve dysfunction and combined ascending aortic dilatation more than 4 to $4.5 \mathrm{~cm} .{ }^{28}$ Russo and colleagues ${ }^{29}$ reported $6 \%$ aortic reoperation after AVR in patients with BAV during 20 years; on closer inspection, however, there were no reoperations for pathology of aortic root. Borger and colleagues ${ }^{30}$ reported an $11 \%$ incidence of ascending aortic complications during 10 years of follow-up after AVR for BAV, including 19 patients undergoing replacement of ascending aorta, 18 patients developing aortic aneurysms, and 1 patient experiencing aortic dissection. They reported no cases of aortic root pathology. Furthermore, in an older report of patients with aneurysms of diverse cause in which the long-term results of separate valve and graft were compared with composite replacement, the Stanford group reported 49 of 255 patients undergoing separate valve and ascending aortic repair coming to late reoperation, of which 35 of the reoperations were on the valve itself and 7 were for aneurysmal dilatation of the sinuses of Valsalva. Of these 7 patients, 5 had acute or chronic dissection and 4 had Marfan syndrome. ${ }^{31}$ Similarly, in the Baylor experience of 277 patients undergoing root- sparing techniques between 1953 and 1992 among 210 operative survivors with long-term follow-up, aortic root aneurysms developed in 9, of whom 8 had Marfan syndrome. ${ }^{32}$ The data to support routine replacement of the sinuses in BAV disease absent Marfan syndrome are, therefore, scant.

A number of patients in our series underwent aortoplasty. The majority of these patients had surgery early in the series. Over time, we have shifted largely away from aortoplasty in favor of graft replacement as more hemostatic grafts diminish the advantage of aortoplasty. Remarkably, of these 65 patients, only 2 have undergone reoperation. We do not, however, advocate this approach as a matter of routine and it is reserved currently for only a small subset of patients in whom the enlargement is mild at most.

The overall survival of patients in our series at 5 and 10 years was $89 \%$ and $79 \%$, respectively, and was comparable to that of age- and gender-matched controls. This is superior to that reported by Sioris and colleagues, ${ }^{33}$ who reported a 10 -year survival of only $57 \%$ for patients undergoing supracoronary replacement of ascending aorta compared with $74 \%$ for patients undergoing the Bentall operation. In their series, however, patients undergoing composite root replacement were younger and less often had concomitant coronary artery disease, as was the case in the Washington University expereince. ${ }^{19}$ Survival in the series from Stanford was also lower than that in ours,

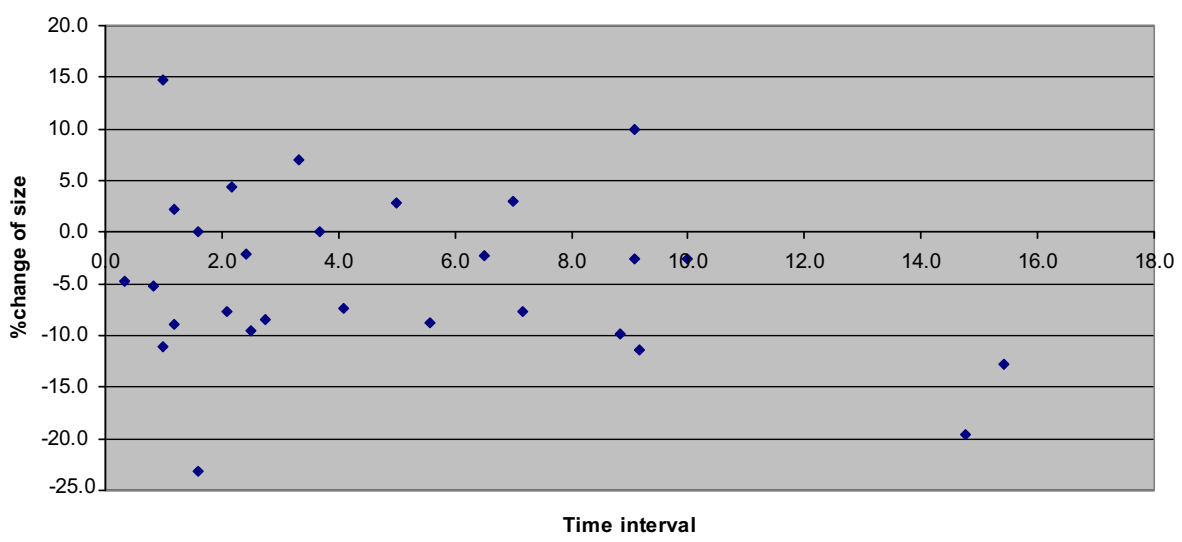

FIGURE 3. Change in aortic root diameter by serial echocardiography versus time in years. 


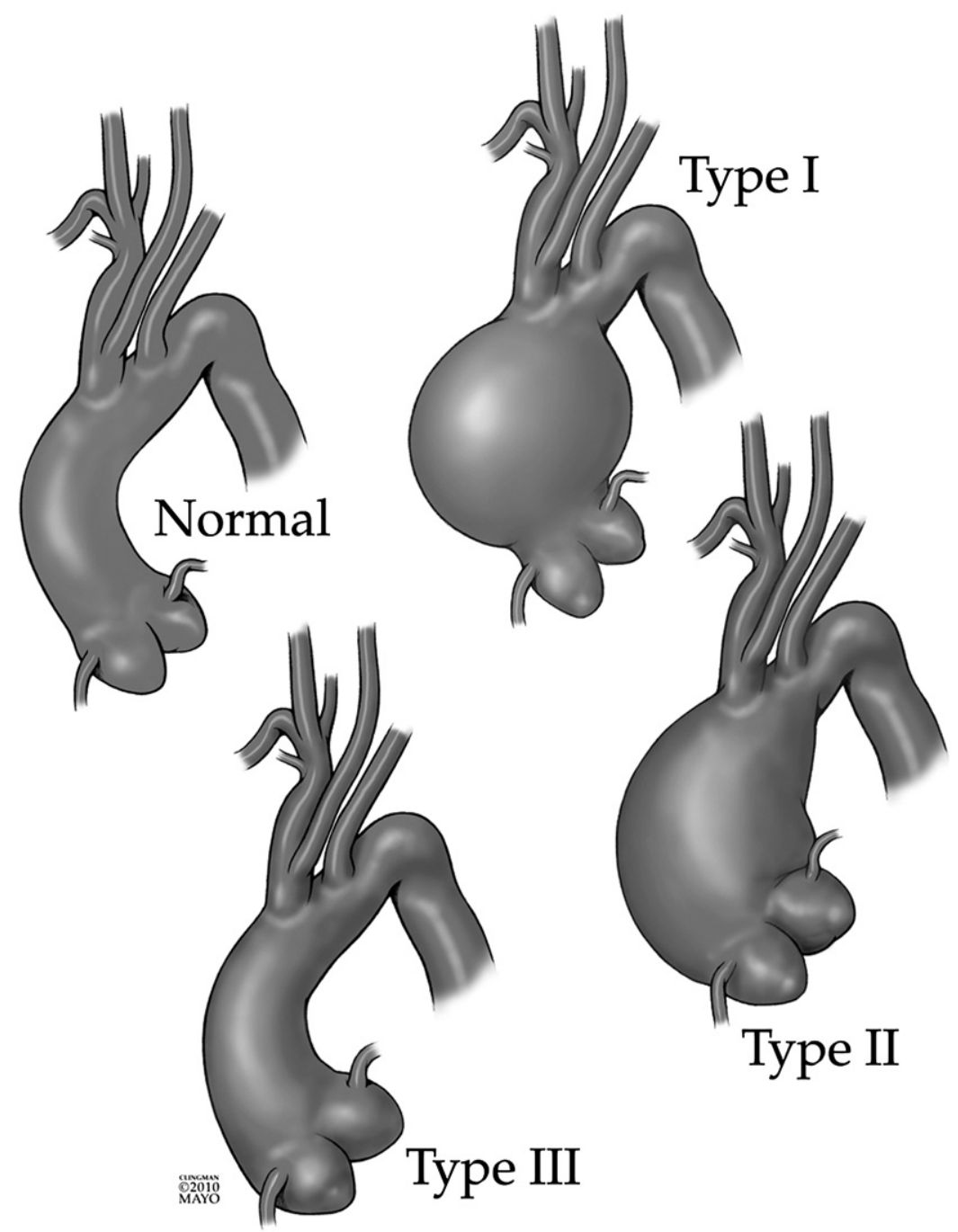

FIGURE 4. In our experience, there are 3 commonly observed phenotypes of aneurysm associated with BAV disease: The most common is supracoronary enlargement with preservation of the sinotubular junction (type 1). The next most common demonstrates ectasia of the ascending aorta and root with effacement of the sinotubular junction (type 2). The least common is strikingly similar in appearance to the aneurysm typical of Marfan syndrome and is confined to the root itself (type 3 ).

with 1-, 5-, and 10-year survival after separate graft and valve replacement of $78 \%, 67 \%$, and $51 \%$, respectively, compared with $85 \%, 80 \%$, and $68 \%$, respectively, after composite root replacement. ${ }^{31}$ Again, in contrast with our series, however, they included patients with aneurysms of various causes. Both sets of authors concluded that there remains a place for a separate supracoronary graft and valve operations in addition to root replacement. The long-term survival in our series suggests that our surgical treatment policy is appropriate and does not reduce the life expectancy in patients with BAV.

\section{Study Limitations}

The principle limitations of our study are a lack of quantitative data concerning the actual sinus dimensions at the time of surgery and incomplete imaging follow-up of the sinus dimensions. In addition, although the maximum follow-up is to 17 years, the mean follow-up is considerably shorter at 3.3 years, placing obvious constraints on our ability to predict with certainty the likelihood of root dilatation over a prolonged period of time. Still, this is a relatively large series of patients with follow-up exceeding 8 years in 50 patients, and we believe the data are clinically useful. The tendency at the Mayo Clinic is to be less aggressive in root replacement than other surgeons have reported, as reflected by the comparable frequency with which separate valve and graft replacements and formal root replacement were performed. Accordingly, our long-term results should represent a "worst case scenario" in terms of the risk of dilatation. Conversely, the lack of follow-up imaging data weakens arguments regarding the actual rate of subsequent enlargement, because the incidence of clinically silent root 
dilatation is unknown. Still, in the end, the most clinically relevant end point for the patient is survival, and our survival data suggest that patients are not experiencing ill consequences from this perspective.

\section{CONCLUSIONS}

Absent quantitative data and a sufficient event rate, we cannot establish an evidence-based threshold number below which the sinuses may be left. It is our general practice, however, to routinely replace the root when it exceeds 5 $\mathrm{cm}$ diameter or the coronary ostia are displaced more than $2 \mathrm{~cm}$ from the surgical annulus, and to leave the root intact when it is less than $4.5 \mathrm{~cm}$ in diameter or the ostia are not displaced. When the root diameter falls between these parameters, we are influenced by the age of the patient, being more aggressive in younger patients who will be at risk for progressive dilatation for a longer period of time and in whom mobilization of less displaced coronary arteries is likely to be easier. We are also influenced by the general phenotype of the root, being more likely to leave the root intact if the sinotubular junction is intact ("type I") and more inclined to replace if effaced (type II or III).

\section{References}

1. Biner S, Rafique AM, Ray I, Cuk O, Siegel RJ, Tolstrup K. Aortopathy is prevalent in relatives of bicuspid aortic valve patients. J Am Coll Cardiol. 2009;53: 2288-95.

2. Dare AJ, Veinot JP, Edwards WD, Tazelaar HD, Schaff HV. New observations on the etiology of aortic valve disease: a surgical pathologic study of 236 cases from 1990. Hum Pathol. 1993;24:1330-8.

3. Nkomo VT, Enriquez-Sarano M, Ammash NM, Melton LJ III, Bailey KR, Desjardins V, et al. Bicuspid aortic valve associated with aortic dilatation. A community-based study. Arterioscler Thromb Vasc Biol. 2003;23:351-6.

4. Pachulski RT, Weinberg AL, Chan K. Aortic aneurysm in patients with functionally normal or minimally stenotic bicuspid aortic valve. Am J Cardiol. 1991;67:781-2.

5. Hahn RT, Roman MJ, Mogtader AH, Devereux RB. Association of aortic dilation with regurgitant, stenotic and functionally normal bicuspid aortic valves. $J \mathrm{Am}$ Coll Cardiol. 1992;19:283-8.

6. Nistri S, Sorbo MD, Marin M, Palisi M, Scognamiglio R, Thiene G. Aortic root dilatation in young men with normal functioning bicuspid aortic valves. Heart. 1999;82:19-22.

7. Crawford MH, Roldan CA. Prevalence of aortic root dilatation and small aortic roots in valvular aortic stenosis. Am J Cardiol. 2001;87:1311-3.

8. Keane MG, Wiegers SE, Plappert T, Pochettino A, Bavaria JE. St John Sutton MG. Bicuspid aortic valves are associated with aortic dilatation out of portion to coexistent valvular lesion. Circulation. 2000;102(suppl III):III-35-9.

9. Yasuda H, Nakatani S, Stugaard M, Tsujita-Kuroda Y, Bando K, Kobayashi J, et al. Failure to prevent progressive dilation of ascending aorta by aortic valve replacement in patients with bicuspid aortic valve: Comparison with tricuspid aortic valve. Circulation. 2003;108(suppl II):II-291-4.

10. Coady MA, Rizzo JA, Hammond GL, Mandapati D, Darr U, Kopf GS, et al. What is the appropriate size criterion for resection of thoracic aortic aneurysms? J Thorac Cardiovasc Surg. 1997;113:476-91.

11. Larson EW, Edwards WD. Risk factors for aortic dissection: a necropsy study of 161 cases. Am J Cardiol. 1984;53:849-55.

12. Bonow RO, Carabello BA, Chatterjee K, de Leon AC Jr, Faxtoon DP, Freed MD, et al. ACC/AHA 2006 guidelines for the management of patients with valvular heart disease: a report of the American College of Cardiology/American Heart
Association Task Force on Practice Guidelines (Writing Committee to Revise the 1998 Guidelines for the Management of Patients With Valvular Heart Disease). J Am Coll Cardiol. 2006;48:e1-148.

13. Cameron DE, Alejo DE, Patel ND, Nwakanma LU, Weiss ES, Vricella LA, et al. Aortic root replacement in 372 Marfan patients: Evolution of operative repair over 30 years. Ann Thorac Surg. 2009;87:1344-50.

14. Zehr KJ, Orszulak TA, Mullany CJ, Matloobi A, Daly RC, Dearani JA, et al. Surgery for aneurysms of the aortic root: a 30-year experience. Circulation. 2004; 110:1364-71.

15. Reece TB, Singh RR, Stiles BM, Peeler BB, Kern JA, Tribble CG, et al. Replacement of the proximal aorta adds no further risk to aortic valve procedures. Ann Thorac Surg. 2007;84:473-8.

16. Rankin JS, Hammill BG, Ferguson TB Jr, Glower DD, O'Brien SM, DeLong ER, et al. Determinants of operative mortality in valvular heart surgery. $J$ Thorac Cardiovasc Surg. 2006;131:547-57.

17. Shahriari A, Eng M, Tranquilli M, Elefteriades JA. Rescue coronary artery bypass grafting (CABG) after aortic composite graft replacement. J Card Surg. 2009;24:392-6.

18. Etz CD, Plestis KA, Homann TM, Bodian CA, Di Luozzo G, Spielvogel D, et al. Reoperative aortic root and transverse arch procedures: a comparison with contemporaneous primary operations. J Thorac Cardiovasc Surg. 2008;136: 860-7.

19. Sundt TM III, Mora BN, Moon MR, Bailey MS, Pasque MK, Gay WA Jr. Options for repair of a bicuspid aortic valve and ascending aortic aneurysm. Ann Thorac Surg. 2000;69:1333-7.

20. Clark TG, Altman DG, De Stavola BL. Quantification of the completeness of follow-up. Lancet. 2002;359:1309-10.

21. Meijboom LJ, Nollen GJ, Merchant N, Webb GD, Groenink M, David TE, et al. Frequency of coronary ostial aneurysms after aortic root surgery in patients with the Marfan syndrome. Am J Cardiol. 2002;89:1135-8.

22. Thanassoulis G, Yip JWL, Filion K, Jamorski M, Webb G, Siu SC, et al. Retrospective study to identify predictors of the presence and rapid progression of aortic dilatation in patients with bicuspid aortic valves. Nat Clin Pract Cardiovasc Med. 2008;5:821-8.

23. Beroukhim RS, Kruzick TL, Taylor AL, Gao D, Yetman AT. Progression of aortic dilation in children with a functionally normal bicuspid aortic valve. Am J Cardiol. 2006;98:828-30

24. Ferencik M, Pape LA. Changes in size of ascending aorta and aortic valve function with time in patients with congenitally bicuspid aortic valves. Am J Cardiol. 2003;92:43-6.

25. La Canna G, Ficarra E, Tsagalau E, Nardi M, Morandini A, Chieffo A, et al. Progression rate of ascending aortic dilation in patients with normally functioning bicuspid and tricuspid aortic valves. Am J Cardiol. 2006;98:249-53.

26. Ferencik M, Pape LA. Changes in size of ascending aorta and aortic valve function with time in patients with congenitally bicuspid aortic valves. Am J Cardiol. 2003;92:43-6.

27. Warnes CA. Bicuspid aortic valve and coarctation: two villains part of a diffuse problem. Heart. 2003;89:965-6.

28. Etz CD, Homann TM, Silovitz D, Spielvogel D, Bodian CA, Luehr M, et al. Long-term survival after the Bentall procedure in 206 patients with bicuspid aortic valve. Ann Thorac Surg. 2007;84:1186-94.

29. Russo CF, Mazzetti S, Garatti A, Ribera E, Milazzo A, Bruschi G, et al. Aortic complications after bicuspid aortic valve replacement: long-term results. Ann Thorac Surg. 2002;74:S1773-6.

30. Borger MA, Preston M, Ivanov J, Fedak PWM, Davierwala P, Armstrong S, et al. Should the ascending aorta be replaced more frequently in patients with bicuspid aortic valve disease? J Thorac Cardiovasc Surg. 2004;128:677-83.

31. Yun KL, Miller DC, Fann JI, Mitchell S, Robbins RC, Moore KA, et al. Composite valve graft versus separate aortic valve and ascending aortic replacement. Is there still a role for the separate procedure? Circulation. 1997;96(suppl II): II-368-75.

32. Lawrie GM, Earle N, DeBakey ME. Long-term fate of aortic root and aortic valve after ascending aneurysm surgery. Ann Surg. 1993;217:711-20.

33. Sioris T, David TE, Ivanov J, Armstrong S, Feindel CM. Clinical outcomes after separate and composite replacement of the aortic valve and ascending aorta. J Thorac Cardiovasc Surg. 2004;128:260-5. 